\title{
Model Sistem Pendukung Keputusan Penentuan Prioritas Perbaikan Produk Elektrikal Dan Mekanikal Dengan Metode AHP Pada Industeri Elektrikal Dan Mekanikal
}

\author{
Aris Martono*1, Padeli $^{2}$ \\ 1,2Program Studi Teknik Informatika Universitas Raharja \\ e-mail : ${ }^{1 *}$ aris.martono@raharja.info, ${ }^{2}$ padeli@,raharja.info
}

\begin{abstract}
Abstrak
PT. Nusa Abadi Elektrika merupakan perusahaan yang bergerak dibidang industri elektrikal dan mekanikal produk seperti penyedia barang dan jasa perbaikan serta ahli dalam instalisasi tenaga listrik menengah dan tinggi. Sistem yang berjalan pada PT. Nusa Abadi Elektrika saat ini dapat dikatakan belum berjalan dengan baik khususnya dibagian administrasi dalam melakukan pekerjaannya, administrasi mengalami kesulitan untuk menentukan produk elektrikal dan mekanikal mana yang akan diperbaiki telebih dahulu, dan dalam proses perbaikan. Penelitian ini menggunakan metode Analythical Hierarchy Process (AHP) untuk membuat model Sistem Pendukung Keputusan (SPK) untuk menentukan alternatif terbaik berdasarkan beberapa kriteria yang ada dan menentukan prioritas utama dalam proses pengambilan keputusan perbaikan produk elektrikal dan mekanikal. Penelitian ini terdapat 3 kriteria, yaitu biaya perbaikan, tingkat kesulitan perbaikan dan waktu pengerjaan barang. Hasil pengujian perhitungan dengan metode AHP dalam menentukan keputusan prioritas perbaikan produk ini menghasilkan perangkingan dengan Consistency Ratio (CR) masing-masing normalisasi matriks tidak melebihi 0,1 atau $10 \%$ dan dapat dikatakan konsisten. Model SPK penggunaan metode AHP ini untuk memudahkan penyelesaian pekerjaan lebih obyektif.
\end{abstract}

Kata Kunci: Sistem Pendukung Keputusan, Administrasi, Analythical Hierarchy Process (AHP)

\begin{abstract}
Abtract
PT. Nusa Abadi Elektrika is a company engaged in the electrical and mechanical product industry, such as a provider of repair goods and services as well as an expert in the installation of medium and high electric power. The system running at PT. Nusa Abadi Elektrika at this time can be said that it has not been going well, especially in the administration division in doing its work, the administration has difficulty determining which electrical and mechanical products will be repaired first, and in the repair process. This study uses the Analythical Hierarchy Process (AHP) method to create a Model of Decision Support System (DSS) to determine the best alternative based on several existing criteria and determine the main priority in the decision-making process for electrical and mechanical product improvement. This research has 3 criteria, namely repair costs, the level of difficulty of repairs and the time to work on the goods. The results of calculation testing using the AHP method in determining the priority decision for product improvement result in a ranking with the Consistency Ratio (CR) of each matrix normalization not exceeding 0.1 or $10 \%$ and can be said to be consistent. The DSS model uses the AHP method to facilitate more objective work completion.
\end{abstract}

Keywords: Decision Support System, Administration, Analythical Hierarchy Process (AHP) 


\section{PENDAHULUAN}

\section{Latar Belakang}

Saat ini penggunaan sistem teknologi informasi pada perusahaan semakin dibutuhkan, begitu juga pada perusahaan yang bergerak dibidang industri elektrikal dan mekanikal, dimana dalam mengerjakan suatu proyek pada proses pengerjaannya dibutuhkan sebuah sistem pengendalian yang terstruktur dengan baik agar meningkatkan efisiensi dan kinerja suatu perusahaan.

PT. Nusa Abadi Elektrika atau disingkat menjadi PT. NAE merupakan perusahaan yang bergerak dibidang industri elektrikal dan mekanikal produk seperti pembuatan atau perakitan Panel Control, Panel ATS, Panel Synchrone, Capasitor Bank, Retrofit Cubibcle dan sebagai penyedia jasa perbaikan, serta ahli dalam memodifikasi dan instalasi tenaga listrik menengah sampai tinggi.

Dalam melakukan proses pekerjaan yang khususnya dibidang jasa perbaikan elektrikal produk pada NAE mempunyai beberapa tahapan-tahapan dimana dalam tahapan tersebut harus melalui beberapa proses, antara lain penerimaan informasi pekerjaan, penginputan data permintaan client, pengadaan meeting pekerjaan, pembuatan form penerimaan pekerjaan, pengiriman \& penerimaan produk perbaikan,pengecekan serta perbaikan produk, pengujian produk hasil perbaikan, memberikan laporan hasil perbaikan dan produk hasil perbaikan tersebut dikembalikan lagi kepada client.

Saat ini NAE khususnya dibagian administrasi dalam melakukan pekerjaanya masih semi komputerisasi seperti melakukan proses pekerjaan jasa perbaikan elektrikal produk contohnya, yaitu pencatatan proyek masuk dan keluar dikerjakan secara manual dengan kertas lalu diinput keMs. Excel, pengecekan dalam perbaikan elektrikal produk secara manual dengan kertas, menentukan keputusan prioritas perbaikan produk masih melihat dengan data-data pekerjaan sebelumnya di Ms.Excel yang dapat dikatakan kurang akurat dan menargetkan waktu pada proses perkerjaan masih manual. Dengan demikian mekanisme pekerjaan tersebut belum sistematis dan terstruktur maka perlu dibuatkan suatu model sistem pendukung keputusan perbaikan produk elektrikal dan mekanikal untuk meminimalisir kesalahan dan waktu proses dalam penentuan prioritas perbaikan produk tersebut. [1]

Oleh karena itu penelitian ini membuat sistem pendukung keputusan penentuan prioritas perbaikan dengan metode analytical hierarchy process yang dapat membantu proses pekerjaan produk elektrikal dan mekanikal di PT. Nusa Abadi Elektrika agar berjalan dengan baik dan meningkatkan efisensi serta kinerja pada perusahaan.

Berdasarkan latar belakang diatas maka permasalahan dapat dirumuskan sebagai berikut:

a. Bagaimana kendala atau permasalahan yang dihadapi oleh karyawan dalam menentukan keputusan prioritas perbaikan produk?

b. Apa yang dihasilkan dari sistem pendukung keputusan dengan menggunakan metode ahp?

c. Berapa tingkat validasi sistem pendukung keputusan penentuan prioritas perbaikan dengan sistem yang diusulkan?

Pembahasan penelitian ini dibatasi pada hal-hal sebagai-berikut:

a. Terfokus pada jasa perbaikan elektrikal produk.

b. Sistem ini meliputi tahapan-tahapan proses dari perkerjaan yang diterima sampai produk siap digunakan.

c. Sistem digunakan oleh bagian administrasi sebagai admin pada aplikasi, dan marketing serta direktur sebagai user.

Metode yang akan digunakan untuk menganalisa penentuan prioritas perbaikan dalam proses pekerjaan adalah Analytical Hierarchy Process (AHP).

Dengan batasan-batasan penelitian di atas maka penelitian ini bertujuan antara-lain :

a. Sistem yang dapat menentukan keputusan prioritas perbaikan produk dengan metode analythical hierarchy processdi PT. Nusa Abadi Elektrika.

b. Membantu para user dalam penentuan keputusan prioritas perbaikan produk.

Sedangkan manfaat system ini adalah memudahkan karyawan dalam proses pekerjaan jasa perbaikan dengan keputusan prioritas perbaikan produk yang akurat. 


\section{METODE PENELITIAN}

\section{Metode Pengumpulan Data}

Dalam melakukan penelitian ini terdapat beberapa metode pengumpulan data, antara-lain :

Dalam metode observasi peneliti mendatangi PT. Nusa Abadi Elektrika dan melakukan pengamatan langsung ke lokasi penelitian.Mengamati dengan cermatberbagai hal yang adadidalam perusahaan serta melakukan pencatatan yang diperlukan untuk mendapatkan suatu informasi yang dapat dikembangkan menjadi suatu penilitian.

Metode wawancara ini adalah proses pengumpulan data yang dilakukan dengan cara tanya jawab langsung kepada Stakeholder bernama bapak Indra Nurpradhana selaku Kepala Gudang yang ditunjuk oleh bapak Handoko Raramenusa selaku Direktur Operasional untuk memberikan informasi yang lebih detail tentang perusahaan yang akan dikembangkan dalam penelitian ini.

Metode studi pustaka adalah metode pengumpulan data yang dilakukan untuk menunjang metode observasi dan wawancara dengan cara mencari informasi yang relevan sesuai dengan penelitian yang dapat diperoleh dari membaca dan mempelajari sumber - sumber kepustakaan dan internet seperti beberapa buku, karangan ilmiah, Jurnal dan laporan penelitian lainnya yang berhubungan dengan penelitian ini.

\section{Analytical Hierarchy Process (AHP)}

Pendekatan dengan analisis proses secara hirarki, terdapat beberapa pengertian--metode Analytical Hierarchy Process (AHP)--antara-lain:

Sebuah konsep untuk pembuatan keputusan berbasis multicriteria (kriteria yang banyak). Beberapa kriteria yang dibandingkan satu dengan yang lainnya (tingkat kepentingannya) adalah penekanan utama pada konsep AHP ini. AHP menjadi sebuah metode penentuan atau pembuatan keputusan, yang menggabungkan prinsip-prinsip subjektifitas dan objektifitas si pembuat SPK atau keputusannya disebut AHP.[2]

Kerangka untuk mengambil keputusan dengan efektif atas persoalan yang kompleks dengan menyederhanakan dan mempercepat proses pengambilan keputusan dengan memecahkan persoalan tersebut ke dalam bagian-bagiannya, menata bagian atau variabel ini dalam suatu susunan hirarki, memberi nilai numerik pada pertimbangan subjektif tentang pentingnya tiap variabel dan mensintesis berbagai pertimbangan ini untuk menetapkan variabel yang mana yang memiliki prioritas paling tinggi dan bertindak untuk mempengaruhi hasil pada situasi tersebut dinamakan AHP.[3]

AHP merupakan salah satu model pengambilan keputusan multi kriteria yang dapat membantu kerangka berpikir manusia di mana faktor logika, pengalaman, pengetahuan, emosi, dan rasa dioptimasikan ke dalam suatu proses sistematis. [4] AHP adalah metode pengambilan keputusan yang dikembangkan untuk pemberian prioritas beberapa alternatif ketika beberapa kriteria harus dipertimbangkan, serta mengijinkan pengambil keputusan (decision makers) untuk menyusun masalah yang kompleks ke dalam suatu bentuk hirarki atau serangkaian level yang terintegrasi. Adapun urutan dalam melakukan pembobotan rekomendasi dengan metode AHP adalah sebagai berikut:

Langkah 1: Menyusun sebuah struktur hierarki permasalahan.

Langkah 2: Membuat matriks perbandingan berpasangan.

Langkah 3: Menghitung bobot/ prioritas dari masing masing variabel.

Berdasarkan definisi metode Analytical Hierarchy Process (AHP) di atas maka dapat disimpulkan bahwa AHP ada sebuah konsep untuk pembuatan sebuah keputusan dengan melihat kriteria kriteria untuk pemberiaan prioritas dalam beberapa alternative yang ada.

Metode Analythical Hierarcy Process (AHP) untuk proses system pengambilan keputusan ini terdapat beberapa langkah antara-lain :

a. Mendefinisikan permasalahan dan penentuan tujuan. Jika AHP digunakan untuk memilih alternatif atau menyusun prioritas alternatif, pada tahap ini dilakukan pengembangan alternatif. 
b. Menyusun masalah kedalam hierarki sehingga permasalahan yang kompleks dapat ditinjau dari sisi yang detail dan terstruktur.

c. Penyusunan prioritas untuk tiap elemen masalah pada hirarki. Proses ini menghasilkan bobot atau kontribusi elemen terhadap pencapaian tujuan sehingga elemen dengan bobot tertinggi memiliki prioritas penanganan. Prioritas dihasilkan dari suatu matriks perbandinagan berpasangan antara seluruh elemen pada tingkat hierarki yang sama.

d. Melakukan pengujian konsitensi terhadap perbandingan antar elemen yang didapatan pada tiap tingkat hirarki.

Terdapat beberapa penelitian yang berkaitan dengan sistem pendukung keputusan pada penelitian ini, untuk mengembangkan dan menyempurnakan sistem ini perlu dilakukan studi pustaka sebagai salah satu dari penerapan metode penelitian yang akan dilakukan, antara lain :

a. Untuk menentukan supplier terbaik berdasarkan nilai preferensi setiap alternatif dengan menggunakan metode Analityc Hierarchy Process (AHP). kriteria-kriteria yang digunakan adalah kualitas, harga, dan waktu pengiriman. Metode AHP adalah suatu metode pengambilan keputusan yang bersifat multikriteria. Setiap kriteria dan sub kriteria dalam hirarki tersebut kemudian ditentukan bobot kriteria terhadap tujuan pemilihan supplier bahan baku. Proses pembobotan tersebut dilakukan dengan menggunakan matriks perbandingan berpasangan yang memperhatikan konsistensi logis.[5

b. Banyaknya faktor yang terlibat dalam perhitungan menjadi kendala pembuat keputusan dalam mengambil kebijakan menentukan jumlah tahu yang akan diproduksi. Sistem pendukung keputusan yang menggunakan metode Fuzzy Tsukamoto diharapkan dapat menghemat waktu dan memperkecil kesalahan perhitungan jumlah produksi, sehingga pembuat keputusan cukup menginputkan data-data yang diperlukan oleh sistem pendukung keputusan. Kemudian sistem pendukung keputusan akan mengolah data-data tersebut dan akan menampilkan keluaran (output) berupa jumlah tahu yang akan diproduksi.[6]

c. Model perencanaan jaringan distribusi produk dengan menggunakan metode Fuzzy Multi Objective programming dengan output model adalah pembukaan packing plant dan gudang penyangga dan jumlah pengiriman produk ke konsumen akhir dengan biaya dan waktu distribusi minimum. Model yang dibangun mampu menjelaskan perubahan ouput jika terjadi perubahan-perubahan parameter yang meliputi permintaan antar daerah pemasaran, biaya transportasi antar daerah pemasaran serta kecepatan kendaraan dalam pengangkutan produk dari pusat distribusi terakhir ke daerah pemasaran.[7]

d. Sistem pendukung Keputusan dengan penerapan metode Analytical Hierarchy Process (AHP) dapat membantu dalam pengambilan keputusan atas permasalahan yang kompleks dengan menyederhanakan prosesnya. Sistem ini dapat membantu pihak pembuat keputusan dalam menentukan karyawan The Best secara cepat dan tepat.[8]

e. Program pengambilan keputusan dalam pemilihan supplier dengan menggunakan metode Analytic Hierarchy Process (AHP). Hasil penelitian ini menunjukkan bahwa dengan adanya aplikasi sistem ini, maka informasi tentang masing-masing supplier dapat diketahui dengan baik. Sehingga, perusahaan dapat meningkatkan laba tahunan secara signifikan sampai $90 \%$ melebihi target yang ditetapkan.[9]

f. Aplikasi masalah keputusan untuk menyelesaikan lebih dari satu kriteria kompleks. Dengan metode ini memungkinkan anda untuk memodelkan struktur hirarki yang menunjukkan hubungan antara pembuat keputusan masalah kompleks, tujuan utama dari masalah, kriteria, sub - kriteria dan alternatif. AHP adalah metode cara yang logis di mana sebuah pengetahuan, pengalaman pikiran dan firasat pembuat keputusan digabungkan untuk memecahkan suatu permasalahan yang kompleks.[10]

g. Metode AHP cocok untuk menganalisa masalah pengambilan keputusan yang kompleks. Metode AHP juga dianggap sebagai salah satu metode sempurna dan termudah untuk membuat sebuah keputusan karena mudah digunakan dan mengurangi ketidak konsistenan dalam opini.[11] 
h. Strategi logistik terbaik perlu mempertimbangkan banyak faktor - faktor yang saling terkait dan canggih. Dengan demikian, penelitian ini mengusulkan framework Analytical Hierarchy Process (AHP) untuk mengevaluasi pengembangan strategi logistik terbalik untuk ritel online. Hal yang paling penting adalah mengumpulkan informasi dan pengetahuan yang relevan untuk membangun hierarki AHP dalam mengevaluasi solusi yang ingin diambil oleh para ahli ketika mereka mempertimbangkan untuk membangun logistik terbalik untuk ritel online dan menggabungkan pendekatan dari perbandingan rank pair-wise comparison (RPC) yang digunakan untuk mengukur bobot relatif di antara kriteria.[12]

i. Pembuatan Decision Support System di dalam pembelian rumah yang nantinya akan membantu calon pembeli rumah dalam menentukan rumah mana yang akan dibeli. Metode pengambilan keputusan yang digunakan dalam sistem ini adalah Analytical Hierarchy Process (AHP) sebagai bentuk model pengambilan keputusan yang cocok untuk masalah multi-kriteria dan multi-alternatif dengan input utamanya adalah persepsi manusia. Dikombinasikan dengan metode Borda yang merupakan salah satu metode pengambilan keputusan kelompok yang dapat menggabungkan hasil analisa perseptual (hasil analisa AHP) dari beberapa pengambil keputusan.[13]

j. Penggunaan metode AHP, sistem pendukung keputusan dapat dibangun dengan membandingkan input dari kategori penilaian dan berat rasio yang telah di tentukan. Sistem ini dapat membantu menentukan kelayakan calon penerima FHP berdasarkan kategori penilaian yang dimasukkan ke dalam sistem. Hasil keluaran dari keputusan apakah calon penerima menerima FHP, diperoleh dari perbandingan nilai lamda dari kategori peringkat bobot dengan nilai bobot dari rasio yang telah ditentukan.[14]

Berdasarkan pembahasan di atas penerapan AHP dalam penentuan prioritas perbaikan komponenkomponen industri elektrikal dan mekanikal, perlu dibuat Sistem Pendukung Keputusan Penentuan Prioritas Perbaikan Produk Elektrikal dan Mekanikal dengan Metode AHP pada PT. Nusa Abadi Elektrika.

\section{Expert Choice 2000}

Dalam penerapan penelitian penggunaan metode AHP ini sebaiknya menggunakan perangkat lunak Expert Choice 2000 sebagai tools. Perangkat lunak ini mendukung collaborative decision dan memfasilitasi grup mambuat keputusan yang lebih efisien, analitis, serta dimungkinkan interaksi real-time dari tim manajemen untuk mencapai consensus on decisions. [15]

Software Expert Choice 2000 ini memiliki keunggulan-keunggulan antara-lain [16]:

a. Data Interchange Mapping, Importing and Exporting. Integrasi dengan eksternal Microsoft Access atau database SQL Server menyediakan konektivitas efisien, dan pelaporan capture data, dan mengurangi waktu entri data dan kesalahan.

b. Multiple Models yaitu kemampuan untuk membuka beberapa model dengan mudah dan secara mudah memindah atau menghapus data dari satu model ke model lain, memudahkan proses pembuatan dan memungkinkan pengguna untuk berjalan side by side skenario untuk expedited analisis dan pengambilan keputusan.

c. Support for Microsoft SQL Models untuk mengkonversi atau membuat model SQL dan menghubungkan ke database $S Q L$ perusahaan yang meningkatkan integrasi, lebih cepat.dalam perhitungan model, model yang lebih besar, dan metode mencari dan menerima yang lebih baik.

d. User Friendly Interface yaitu memungkinkan pengguna melihat informasi dokumen saat melakukan judgments dari data grid.

e. Enhanced Reporting yaitu fungsi eksternal untuk mengedit, menciptakan hubungan dengan data perusahaan, melihat data, dan menghilangkan ketidak-konsistenan menyediakan fleksibilitas yang lebih besar dan hasil yang lebih baik secara keseluruhan.

f. Expert Choice Update untuk meng-update software secara online menjamin pengguna dapat mengakses perangkat lunak terbaru. 


\section{HASIL DAN PEMBAHASAN}

\section{Pengambilan Keputusan Multi Kriteria}

Pengambilan keputusan multi kriteria dengan metode AHP ini dikembangkan untuk pemberian prioritas dengan beberapa alternative yang ada. Beberapa kriteria harus dipertimbangkan, serta mengijinkan pengambil keputusan untuk menyusun permasalahan yang kompleks ke dalam suatu bentuk hirarki. Metode AHP ini digunakan untuk memecahkan masalah yang kompleks dan tidak terstruktur ke dalam kelompok - kelompok, dengan mengatur kelompok tersebut ke dalam suatu hirarki. Kemudian memasukkan nilai numerik sebagai pengganti persepsi manusia dalam melakukan perbandingan relatif. Dengan suatu sintesis maka dapat ditentukan elemen mana yang mempunyai prioritas tertinggi.

Langkah-langkah yang harus dilakukan untuk menentukan pemilihan prioritas perbaikan produk elektrikal dan mekanikal ini antara-lain:

\section{Mendefinisikan Masalah}

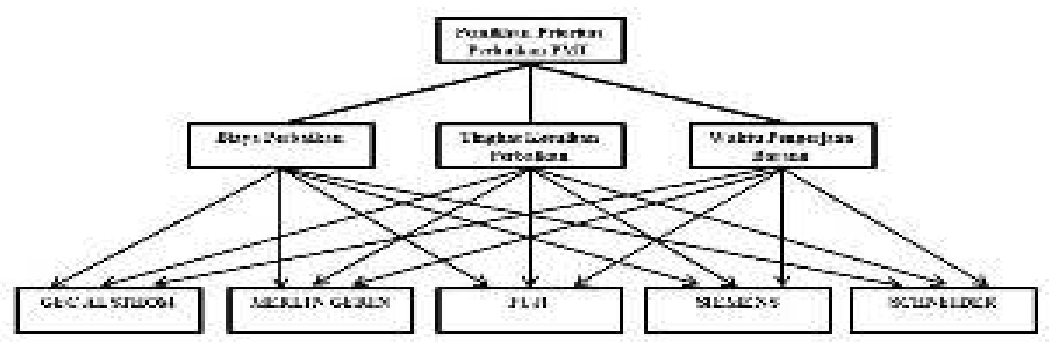

Gambar 1. Struktur HirarkiDalam AHP

Gambar 1 diatas yaitu untuk mendefinisikan masalah langkah awal yang harus dilakukanyaitu menyusun sebuah struktur hirarki untuk mengidentifikasi permasalahan yang kompleks agar permasalahan dapat diuraikan menjadi elemen pokoknya, elemen pokok ini diuraikan lagi kedalam bagian-bagiannya lagi, dan seterusnya secara hirarkis. Susunan terdiri dari goal atau tujuan, kriteria, alternatif.

Tabel 1. Skala Penilaian Perbandingan Berpasangan

\begin{tabular}{|c|l|}
\hline $\begin{array}{c}\text { Intensitas } \\
\text { Kepentingan }\end{array}$ & \multicolumn{1}{c|}{ Ketarangan } \\
\hline 1 & Kedua elemen sama pentingnya \\
\hline 3 & $\begin{array}{l}\text { Elemen yang satu sedikit lebih penting dari pada elemen yang } \\
\text { lainnya }\end{array}$ \\
\hline 5 & Elemen yang satu lebih penting dari pada yang lainnya \\
\hline 7 & Satu elemen jelas lebih mutlak penting dari pada elemen lainnya \\
\hline 9 & Satu elemen mutlak penting daripada elemen lainnya \\
\hline $2,4,6,8$ & $\begin{array}{l}\text { Nilai-nilai antara dua nilai pertimbangan-pertimbangan yang } \\
\text { berdekatan }\end{array}$ \\
\hline
\end{tabular}


Tabel 1 diatas menjelaskan penilaian setiap hirarki dinilai melalui perbandingan berpasangan. Untuk bermacam-macam persoalan, skala $1 \mathrm{~s} / \mathrm{d} 9$ merupakan skala terbaik dalam mengekpresikan pendapat. Skala $1 \mathrm{~s} / \mathrm{d} 9$ ditetapkan sebagai pertimbangan dalam sebuah matriks untuk membandingkan elemen satu dengan elemen yang lain terhadap kriteria yang sudah ditentukan.

\section{Penentuan Prioritas Elemen}

a. Langkah pertama dalam menentukan prioritas elemen yaitu dengan membuat matriks perbandingan berpasangan dengan elemen secara berpasangan sesuai kriteria yang sudah ditentukan. Matriks perbandingan berpasangan diisi menggunakan bilangan dengan skala $1 \mathrm{~s} / \mathrm{d} 9$.

b. Untuk memberi nilai pada kriteria yang sudah ditentukan menggunakan skala $1 \mathrm{~s} / \mathrm{d} 9$ yaitu memberi nilai pada baris kriteria yang dipilih, sedangkan untuk kriteria yang tidak dipilih, dengan cara memberi nilai 1 per nilai yang dipilih pada baris kriteria yang tidak dipilih. Nilai 1 yang menyerong (garis miring hampir vertical) adalah cara mudah mengisi records pada tabel karena perbandingan kriterianya sama, contoh kriteria biaya perbaikan dengan biaya perbaikan, tingkat kesulitan perbaikan dengan tingkat kesulitan perbaikan dan waktu pengerjaan barang dengan waktu pengerjaan barang.

2. Sintesis

Untuk menentukan prioritas keseluruhan maka pertimbangan-pertinmbangan terhadap perbandingan berpasangan perlu disintesis. Dalam hal ini, hal-hal yang harus dilakukan yaitu:

a. Menjumlahkan nilai dari setiap kolom pada matriks.

b. Membagi setiap nilai dari kolom dengan total jumlah kolom yang bersangkutan agar memperoleh normalisasi matriks.

c. Menjumlahkan nilai dari setiap baris dan membaginya dengan jumlah elemen yang sudah ditentukan untuk mendapatkan priority vector atau nilai rata-rata dari hasil perhitungan.

3. Menghitung Consistency Index (CI)

Rumus:

$\mathrm{CI}=($ lamda maks-n) $/(\mathrm{n}-1)$

Dimana $\mathrm{n}=$ banyaknya elemen

Untuk menghitung nilai lamda maks yaitu mengalihkan setiap kolom total jumlah pada matriks perbandingan dengan kolom priority vector hingga menjadi elemen pertama, kedua dan seterusnya serta menjumlahkan masing-masing elemen yang sudah dikelompokkan.

4. Menghitung Consistency Ratio (CR)

Rumus:

$\mathrm{CR}=\mathrm{CI} / \mathrm{IR}$

Dimana $=$ Consistency Ratio

$\mathrm{CI}=$ Consistency Index

$\mathrm{IR}=$ IndexRandom Consistency

Berikut daftar indeks random konsistensi (RI):

Tabel 2. Daftar Indeks Random Konsistensi (RI)

\begin{tabular}{|c|c|c|c|c|c|c|c|c|c|c|c|c|c|c|}
\hline 1 & 2 & 3 & 4 & 1 & $a$ & 7 & 8 & 9 & 10 & 11 & 17 & 14 & 14 & 13 \\
\hline 000 & 000 & 0,58 & 000 & 1,12 & 1,34 & 1,32 & 1,41 & 1,45 & 1,49 & 1,51 & 1,43 & 1,56 & 1,57 & 1,59 \\
\hline
\end{tabular}

Tabel 2 yaitu, dalam pembuatan sebuah keputusan, tingkat konsistensi penting untuk diperhatikan karena kita tidak menginginkan keputusan berdasarkan pertimbangan dengan konsistensi yang rendah dengan nilai maksimal Consistency ratio (CR) kurang dari 0,1 atau 10\%. Karena CR dibawah ini sudah mendapatkan nilai kurang dari 0,1 atau $10 \%$ maka dapat melanjutkan langkah berikutnya, jika CR lebih dari 0,1 atau $10 \%$ maka hal yang harus dilakukan yaitu mengulang pengisian nilai-nilai pada tabel. Berikut perhitungan metode AHP yang sudah dianalisis. 
ISSN : $2356-5195$

Online ISSN: 2654 - 8704

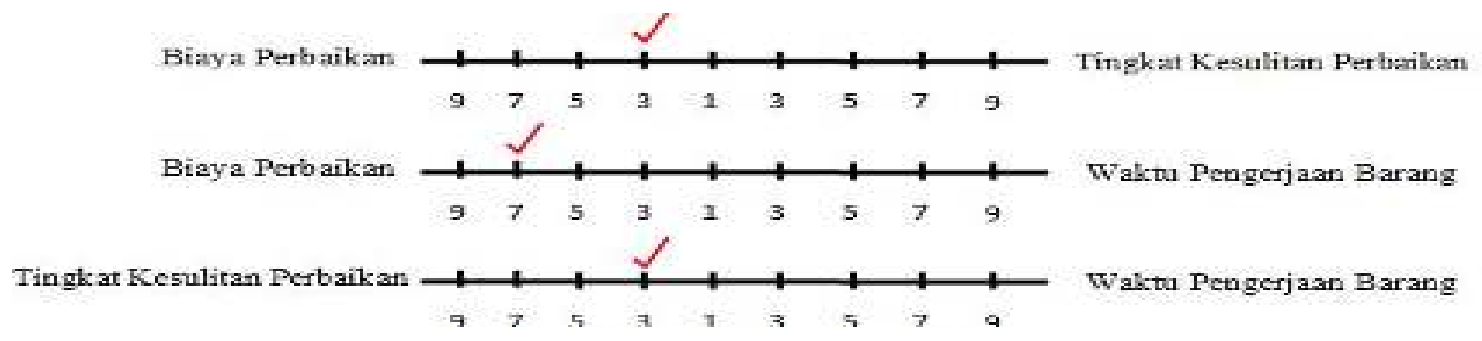

Gambar 2. Skala Perbandingan Terhadap Kriteria Dengan 3 Elemen

Gambar 2 adalah skala perbandingan terhadap kriteria dengan 3 elemen yaitu biaya perbaikan, tingkat kesulitan perbaikan dan waktu pengerjaan barang yang dimana skala penilaian tersebut diperoleh dari beberapa sumber dari perusahaan.

Tabel 3. Matriks Perbandingan Kriteria

\begin{tabular}{|c|c|c|c|}
\hline secinestar & 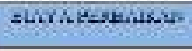 & 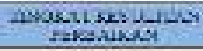 & 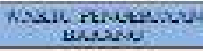 \\
\hline 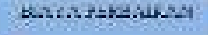 & 1 & 3 & 7 \\
\hline 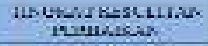 & $n, 3,333$ & 1 & $3^{2}$ \\
\hline 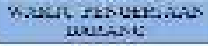 & 0.3 .4286 & 0,33333 & 3 \\
\hline newat & 1.47610 & 4,3333 & 11 \\
\hline
\end{tabular}

Tabel 3 adalah matriks perhitungan perbandingan kriteria yang dimana nilai-nilai tersebut didapatkan dari skala perbandingan kriteria pada gambar 2 dan cara perhitungannya dapat dilihat pada tahap 2 Penentuan Prioritas elemen diatas.

Tabel 4. Normalisasi Matriks Nilai Kriteria

\begin{tabular}{|c|c|c|c|c|c|}
\hline Nerdestx & $\begin{array}{l}\text { mine } \\
\text { PEsE.taxis }\end{array}$ & 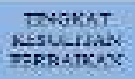 & 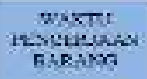 & Fowith & $\begin{array}{l}\text { IPEnserm } \\
\text { VECTDS. }\end{array}$ \\
\hline FERBAIRex & 10.07742 & 01,600231 & 1., 0.56 .36 & $2,010)(1)$ & $4, \operatorname{nos} 20$ \\
\hline 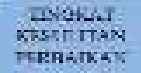 & 0.22 .581 & $0,2.31: 7$ & 0.27273 & $0,720.30$ & 11,24310 \\
\hline 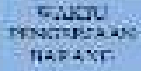 & 0.09677 & 0,07692 & 0.09091 & 0.26161 & 0.06820 \\
\hline
\end{tabular}

Tabel 4 diatas adalah hasil perhitungan normalisasi matriks nilai kriteria dari tabel 3 untuk penjelasan perhitungannya dapat dilihat pada tahap 3 Sintesis diatas.

Tabel 5. Perhitungan Lamda Max, CI dan CR

\begin{tabular}{|r|l|}
\hline Lamda Max & 3,010784914 \\
\hline $\mathrm{CI}=$ & 0,005392457 \\
\hline $\mathrm{CR}=\mathrm{CI} / \mathrm{IR}=$ & 0,009297340 \\
\hline
\end{tabular}

Untuk perhitungan lamda max, CI dan CR diatas dapat dilihat pada tahap 4 Menghitung Consistency Index (CI) dan tahap 5 Menghitung Nilai Consistency Ratio (CR) (lihat tabel 5 diatas). Nilai CR diatas tidak lebih dari $0,1 / 10 \%$ maka dapat dilakukan proses perhitungan selanjutnya 


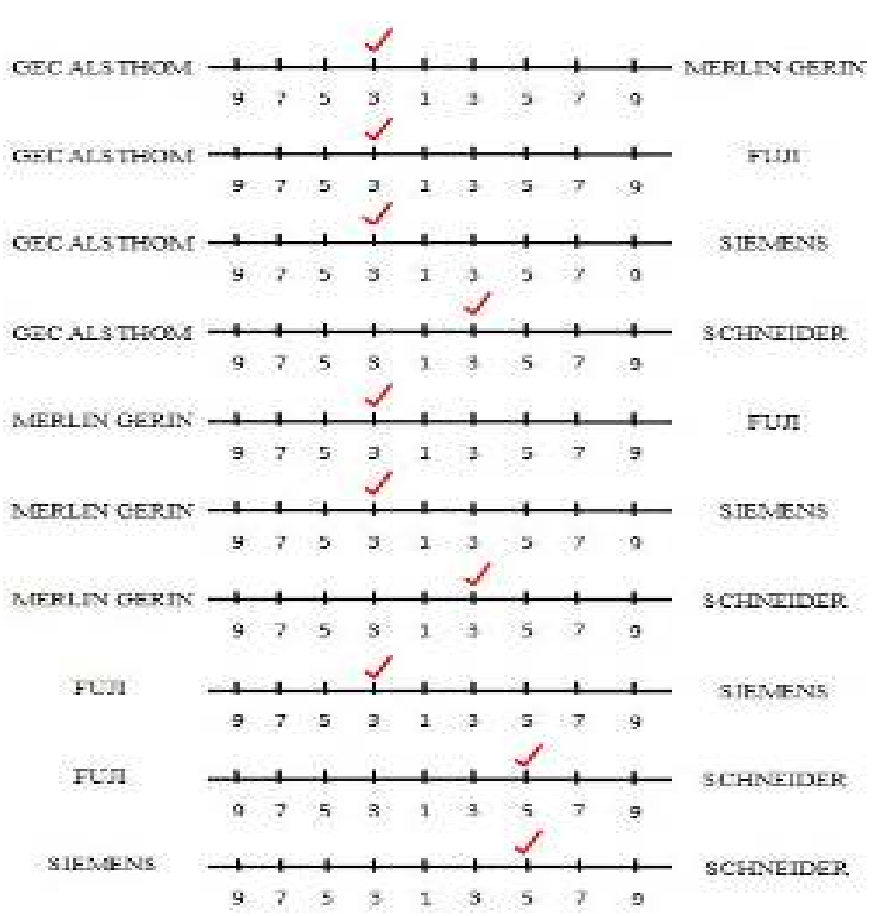

Gambar 3. Skala Perbandingan Alternatif Terhadap Kriteria Biaya Perbaikan

Gambar 3 diatas adalah skala perbandingan alternatif terhadap kriteria biaya perbaikan dengan 5 elemen yaitu gec alsthom, merlin gerin, fuji, siemens dan schneider yang dimana skala penilaian tersebut didapatkan dari beberapa sumber dari perusahaan di atas.

Tabel 6. Matriks Perbandingan Alternatif Terhadap Kriteria Biaya Perbaikan

\begin{tabular}{|c|c|c|c|c|c|}
\hline $\begin{array}{l}\text { maza } \\
\text { TEmanikes }\end{array}$ & $\begin{array}{l}\text { afe } \\
\text { MLSTHose }\end{array}$ & $\operatorname{cosec} 1 x$ & Fus & semens & SCHENEAHS \\
\hline A. ETreon & \pm & 3 & 3 & 3 & 0,33333 \\
\hline sisents & 0.33333 & 1 & 3 & 3 & 0.33333 \\
\hline FI: & 0,33333 & 0.33333 & 2 & 3 & 0.2 \\
\hline SAmens & 0.33333 & 0.33333 & 0.33333 & 1 & 0.2 \\
\hline SCEDEIDER & 3 & 3 & 5 & 5 & I \\
\hline resenast & 5 & 7,60067 & 12.33 .33 .3 & is & 2.06667 \\
\hline
\end{tabular}

Tabel 6 diatas adalah matriks perhitungan perbandingan alternatif terhadap kriteria biaya perbaikan yang dimana perhitungannya dapat dilihat pada tahap 2: Penentuan Prioritas elemen diatas. 
Tabel 7 Normalisasi Matriks Nilai Alternatif Terhadap Kriteria Biaya Perbaikan

\begin{tabular}{|c|c|c|c|c|c|c|c|}
\hline $\begin{array}{c}\text { maik } \\
\text { makawh }\end{array}$ & c50 & rontrs: & run & tmoss & sarcara. & $x=0$ & revarti \\
\hline 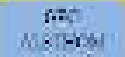 & 0,20090 & 0.39500 & 0.24321 & 0.20000 & 0.16129 & L. 19581 & $0,239=7$ \\
\hline $\begin{array}{l}\text { Nenes } \\
\text { sersab? }\end{array}$ & v.cess 7 & $0.1504 !$ & ง. 24324 & 0.20000 & 0.16129 & c.50104 & 0.10031 \\
\hline हैखा & 0,66657 & 0,54345 & ง.ua 10 s & 0,20000 & 0.09627 & 6,48800 & 0.09760 \\
\hline भनजm & 0,50067 & 0,4345 & 0.02703 & A. $n \in 5: i$ ? & 0,00677 & $0.30 u e$ : & a.afin:2 \\
\hline $3 \mathrm{HV}=\mathrm{T}=\mathrm{k}$ & c.souce & 0,30000 & $0.405+1$ & 0.33333 & 0,48387 & 2,21392 & 0,44278 \\
\hline
\end{tabular}

Tabel 7 diatas adalah hasil perhitungan normalisasi matriks nilai alternatif terhadap kriteria biaya perbaikan dari tabel 6 untuk penjelasan perhitungannya dapat dilihat pada tahap 3 Sintesis diatas.

Tabel 8. Perhitungan Lamda Max, CI dan CR

\begin{tabular}{|r|l|}
\hline Lamda Max & 5,445668356 \\
\hline $\mathrm{CI}=$ & 0,111417089 \\
\hline $\mathrm{CR}=\mathrm{CI} / \mathrm{IR}=$ & 0,099479544 \\
\hline
\end{tabular}

Untuk perhitungan lamda max, CI dan CR diatas dapat dilihat pada tahap 4: Menghitung Consistency Index (CI) dan tahap 5: Menghitung Nilai Consistency Ratio (CR) (lihat tabel 8 diatas). Nilai CR diatas tidak lebih dari 0,1 / 10\% maka dapat dilakukan proses perhitungan selanjutnya.

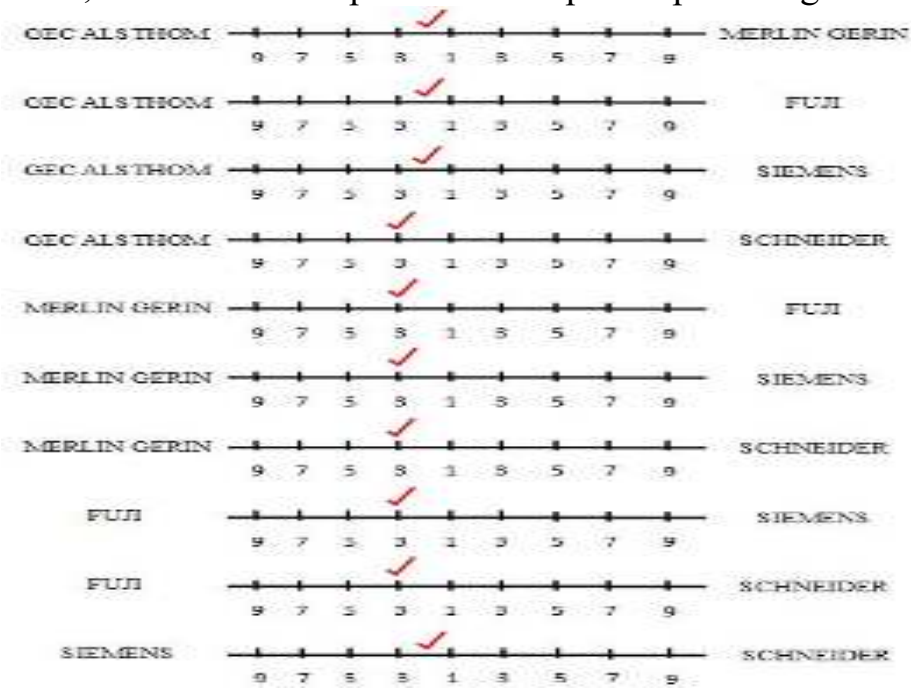

Gambar 4. Skala Perbandingan Alternatif Terhadap Kriteria Tingkat Kesulitan Perbaikan

Gambar 4 diatas adalah skala perbandingan alternatif terhadap kriteria tingkat kesulitan perbaikan dengan 5 elemen yaitu gec alsthom, merlin gerin, fuji, siemens dan schneider yang dimana skala penilaian tersebut didapatkan dari beberapa sumber di perusahaan. 
Tabel 9. Matriks Perbandingan Alternatif Terhadap Kriteria Tingkat Kesulitan Perbaikan

\begin{tabular}{|c|c|c|c|c|c|}
\hline 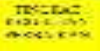 & $\cos x=$ & $x$ & $r \in$ & teses: & SADSElle: \\
\hline astopery & $=$ & I & $=$ & $z$ & $=$ \\
\hline $\lim _{x}$ & 30 & r & a & 3 & 3 \\
\hline $\mathrm{FUT}$ & 8.2 & D:ss<ts & 1 & 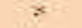 & 3 \\
\hline 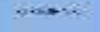 & $\ldots$ & tosises & $10=282=$; & 1 & $=$ \\
\hline strexes. & 2,33593 & G:33523 & 0.33333 & 0.5 & I \\
\hline$A x=$ & $2 n: x \times 1 x$ & 1 & MAPART & N.. & 72 \\
\hline
\end{tabular}

Tabel 9 diatas adalah matriks perhitungan perbandingan alternatif terhadap kriteria tingkat kesulitan perbaikan yang dimana perhitungannya dapat dilihat pada tahap 2: Penentuan Prioritas elemen diatas.

Tabel 10. Nomalisasi Matriks Nilai Alternatif Terhadap Kriteria Tingkat Kesulitan Perbaikan

\begin{tabular}{|c|c|c|c|c|c|c|c|}
\hline 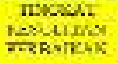 & usuive & sates & Fin & stourens? & 8. $H$ Nenth & rienth & $\begin{array}{l}\text { Aucesis: } \\
\text { rutos: }\end{array}$ \\
\hline $\begin{array}{l}50 \\
1030\end{array}$ & 0,35204 & a.secona & n, $300 \times 06$ & $0,210<3$ & $0.2500 \mathrm{n}$ & $1 . f i 1317$ & $n, a \geq 2100$ \\
\hline $\begin{array}{l}\text { vestrs } \\
\text { cers }\end{array}$ & 0,17647 & $0.2 . \operatorname{sen} n a$ & n. 4 sares: & 0.31579 & 0.25000 & 1.71226 & 0.25645 \\
\hline 배․ & $0,176-17$ & 0.083333 & 0,15000 & 0,31679 & 0,250000 & 0.37559 & 1. 29512 \\
\hline spisin: & 0.17647 & 0.043333 & U.0swoce & $0.10 \leq 26$ & 0,16657 & 0.54273 & 0.736 .35 \\
\hline yctivents. & 0.11765 & $0 . n 33.333$ & n. $0 \sin 0 \mathrm{c}$ & a.nefzes & 0.08 .323 & 0.38605 & 0.07730 \\
\hline
\end{tabular}

Tabel 10 diatas adalah hasil perhitungan normalisasi matriks nilai alternatif terhadap kriteria tingkat kesulitan perbaikan dari tabel 9 untuk penjelasan perhitungannya dapat dilihat pada tahap 3 Sintesis diatas.

Tabel 11. Perhitungan Lamda Max, CI dan CR

\begin{tabular}{|r|r|}
\hline Lamda Max & 5,402860337 \\
\hline $\mathrm{CI}=$ & 0,100715084 \\
\hline $\mathrm{CR}=\mathrm{CI} / \mathrm{IR}=$ & 0,089924182 \\
\hline
\end{tabular}

Untuk perhitungan lamda max, CI dan CR diatas dapat dilihat pada tahap 4 Menghitung Consistency Index (CI) dan tahap 5 Menghitung Nilai Consistency Ratio (CR) (lihat tabel 11 diatas). Nilai CR diatas tidak lebih dari 0,1 / 10\% maka dapat dilakukan proses perhitungan selanjutnya. 
ISSN : $2356-5195$

Online ISSN: 2654 - 8704

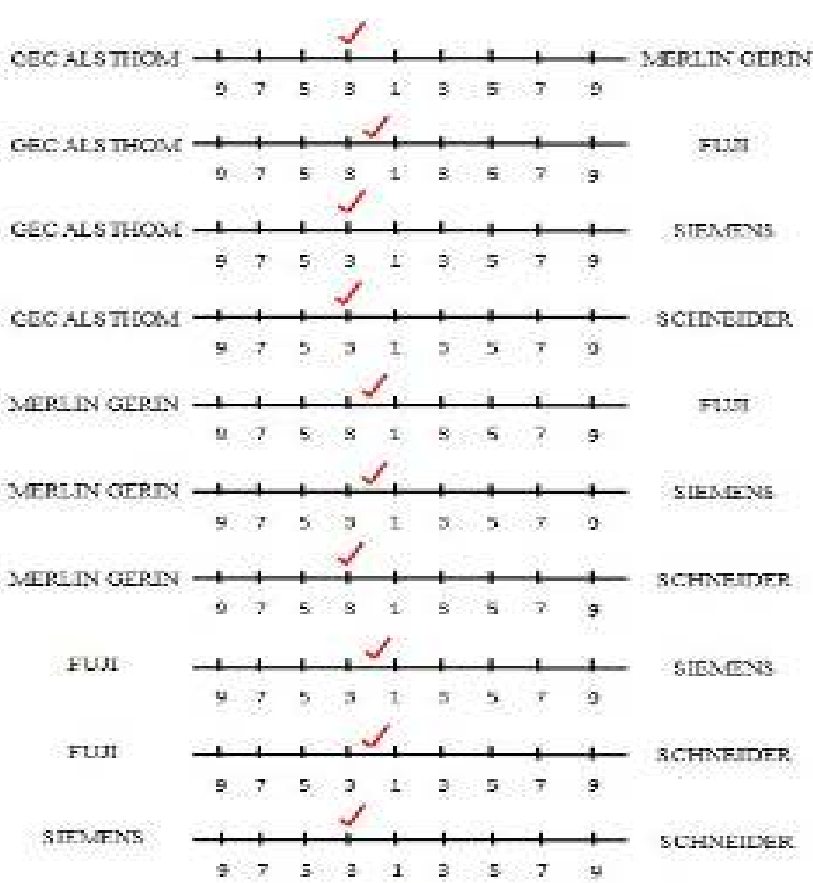

Gambar 5. Skala Perbandingan Alternatif Terhadap Kriteria Waktu Pengerjaan Barang

Gambar 5 diatas adalah skala perbandingan alternatif terhadap kriteria waktu pengerjaan barang dengan 5 elemen yaitu gec alsthom, merlin gerin, fuji, siemens dan schneider dimana skala penilaian tersebut didapatkan dari beberapa sumber dari perusahaan.

Tabel 12. Matriks Perbandingan Alternatif Terhadap Kriteria Waktu Pengerjaan Barang

\begin{tabular}{|c|c|c|c|c|c|}
\hline 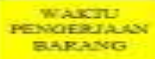 & $\begin{array}{c}\text { CEe } \\
\text { Axstroout }\end{array}$ & $\begin{array}{l}\text { NePI } \\
\text { Cents }\end{array}$ & run & stences & scantuder \\
\hline $\begin{array}{l}\text { Gec } \\
\text { A.S Impes: }\end{array}$ & 1 & 3 & 2 & 3 & 2 \\
\hline $\begin{array}{l}\text { Mepros } \\
\text { derens }\end{array}$ & 0.33333 & 1 & 2 & 2 & 3 \\
\hline Fü & 0.5 & 0,5 & 1 & 2 & 2 \\
\hline stenows & 0.3333 .3 & 0.5 & 0.5 & I & 3 \\
\hline scrateiang: & 0.33333 & 0.33333 & 0.5 & 0.33333 & 1 \\
\hline Jusent & 2,5 & 5,33333 & D & 8,33333 & 12 \\
\hline
\end{tabular}

Tabel 12. diatas adalah matriks perhitungan perbandingan alternatif terhadap kriteria waktu pengerjaan barang yang dimana perhitungannya dapat dilihat pada tahap 2 Penentuan Prioritas elemen diatas. 
Tabel 13. Normalisasi Matriks Nilai Alternatif Terhadap Kriteria Waktu Pengerjaan Barang

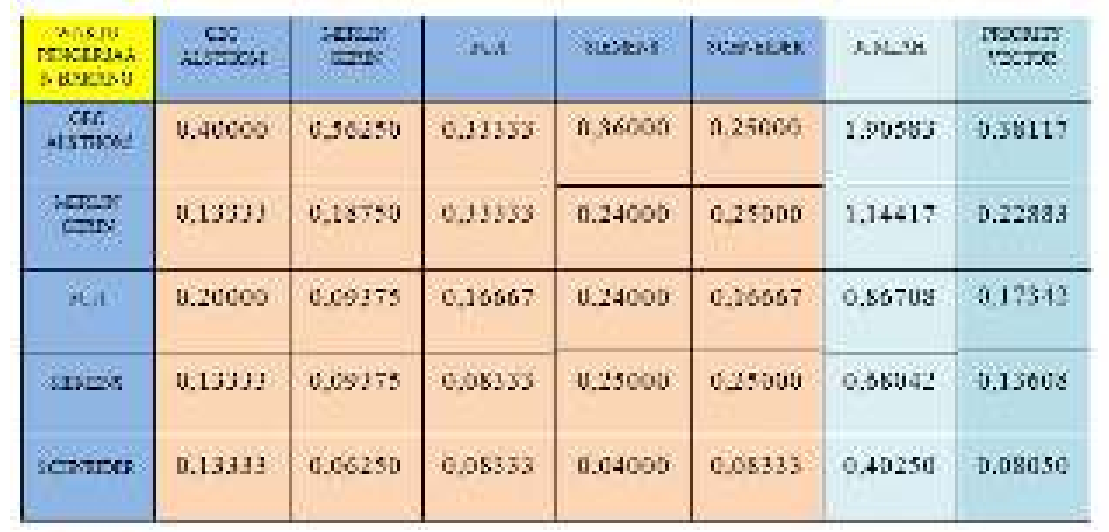

Tabel 13 diatas adalah hasil perhitungan normalisasi matriks nilai alternatif terhadap kriteria waktu pengerjaan barang dari tabel 12 untuk penjelasan perhitungannya dapat dilihat pada tahap 3 Sintesis diatas.

Tabel 14. Perhitungan Consistency Index (CI) dan Consistency Ratio (CR)

\begin{tabular}{|r|r|}
\hline Lamda Max $=$ & 5,313888889 \\
\hline $\mathrm{CI}=$ & 0,078472222 \\
\hline $\mathrm{CR}=\mathrm{CI} / \mathrm{IR}$ & 0,070064484 \\
\hline
\end{tabular}

Untuk perhitungan lamda max, CI dan CR diatas dapat dilihat pada tahap 4 Menghitung Consistency Index (CI) dan tahap 5 Menghitung Nilai Consistency Ratio (CR) (tabel 14 diatas). Nilai CR diatas tidak lebih dari 0,1 / 10\% maka dapat dilakukan proses perhitungan selanjutnya.

Tabel 15. Peringkat Prioritas Perbaikan.

\begin{tabular}{|c|c|c|}
\hline 1 & Schneider & 0,322001118 \\
\hline 2 & Gec Alsthom & 0,271997435 \\
\hline 3 & Merlin Gerin & 0,197516723 \\
\hline 4 & Fuji & 0,127994105 \\
\hline 5 & Siemen & 0,080490619 \\
\hline
\end{tabular}

\section{Menghitung Hasil Peringkat Prioritas Perbaikan}

a. Nilai priority vector matriks perbandingan kriteria elemen pertama, kedua dan ketiga dikalihkan dengan nilai priority vector matriks perbandingan alternatif terhadap kriteria elemen pertama, kedua, dan ketiga lalu masing-masing elemen dikelompokkan serta elemen yang sudah dikelompokkan dijumlahkan.

b. Nilai terbesar menjadi prioritas utama perbaikan.(lihat tabel 15 di atas).

\section{KESIMPULAN}

Berdasarkan permasalahan dan pembahasan di atas maka hal ini dapat disimpulkan bahwa model sistem pendukung keputusan penentuan prioritas perbaikan produk elektrikal dan mekanikal antara-lain:

a. Kendala atau permasalahan yang dihadapi oleh karyawan saat ini adalah dalam menentukan keputusan prioritas perbaikan produk-produk tersebut masih semi komputerisasi dengan kertas 
sebagai media pencatatan dan ms.excel. Referensi dalam penentuan prioritas perbaikan dengan mencari data melalui ms.excel dan data dari media kertas kadang-kadang hilang. Hal ini tentu sangat menyulitkan karyawan dalam proses pekerjaanya.

b. Melakukan analisis model SPK dengan metode AHP untuk penentuan prioritas produk-produk tersebut.

c. Pengujian model SPK dengan metode AHP yang menghasilkan perangkingan dengan Consistency Ratio (CR) masing-masing normalisasi matriks tidak melebihi 0,1 atau $10 \%$ agar dicapai hasil yang konsisten.

\section{SARAN}

a. Perencanaan penentuan prioritas dengan metode AHP agar diperoleh urutan produk-produk yang diperbaiki lebih obyektif dan memuaskan pelayanan penggunanya.

b. Hasil analisis model SPK dengan metode AHP yang akurat dan presisi yang lebih baik.

c. Penerapan model SPK ini dengan pembuatan system berbasis computer sehingga memudahkan para penggunanya untuk pengambilan keputusan penentuan prioritas perbaikan produk-produk tersebut.

\section{DAFTAR PUSTAKA}

[1] Tilaar, F. T.( 2020). Sistem Penunjang Keputusan Perbaikan Produk Elektrikal. Tangerang: Universitas Raharja.

[2] Utama, D. N. (2017). Sistem Penunjang Keputusan Filosofi Teori dan Implementasi. Yogyakarta: Garudhawaca.

[3] Salmon, \& Harpad, B. (2018). Penerapan Metode Analytical Hierarchy Process (AHP) pada Pemilihan Staf Laboratorium Komputer STMIK Widya Cipta Dharma Samarinda. Samarinda: Jurnal SEBATIK, Vol.22 No.1. ISSN: 1410-3737.

[4] Alfiansyah, R., Astuti, U.P., \& Dhani, M. R. (2017). Human Reliability Assesment pada Produksi AMDK dengan Metode HEART dan Sistem Pendukung Keputusan dalam Menentukan Rekomendasi Berbasis AHP (Analitical Hierarchy Process). Surabaya: Semintar Nasional K3 PPNS, Vol.1 No.1. ISSN: 2581-2653.

[5] Belo, A. M., Susestyo, J., \& Asih, E. W. (2016). Analisis Pemilihan Supplier Bahan Baku untuk Produksi dengan Menggunakan Metode Analytic Hierarchy Process (AHP). Yogyakarta: Jurnal Rekavasi, Vol.4 No.2. ISSN: 2338-7750.

[6] Nurmuslimah, S., \& Sriwijaya, H. (2018). Sistem Pendukung Keputusan Penentuan Jumlah Produksi Tahu Menggunakan Metode Fuzzy Tsukamoto. Surabaya: Seminar Nasional Sains dan Teknologi.

[7] Viarani, S. O., Henmaidi, \& Adi, A. H. (2018). Model Jaringan Distribusi Produk dengan Pendekatan Fuzzy Multi Objective Programming. Thesis, Sumatera: Jurnal JOSI. Vol.17 No.1.

[8] Andharsaputri, R. L. (2017). Sistem Pendukung Keputusan dengan Penerapan Metode AHP (Analythical Hierarchy Process) dalam Pemilihan The Best Telesales. Pontianak: Jurnal Bianglala Informatika, Vol.5 No.2. ISSN: 2338-8145. 
[9] Junaedy, Zaman, B., \& Yunus, A. (2018). Implementasi Metode AHP dengan Multi Parameter pada Sistem Penunjang Keputusan Pemilihan Supplier. Makassar: Jurnal INSYPRO, Vol.3 No.1. ISSN: 2579-468X.

[10] Terzi, E. (2019). Analythic Hierarchy Process (AHP) to Solve Complex Decision Problems. Southeast Europe: Journal of Soft Computing, Vol.8 No.1. ISSN: 2233-1859.

[11] Aziz, N. F., Sorooshian, S., \& Mahmud, F. (2016). MCDM-AHP Method In Decision Makings. Malaysia: ARPN JEAS Journal, Vol.11 No.11. ISSN: 1819-6608.

[12] Lee, P. H., Hsu, S. C., \& Chen, S. Y. (2018). An AHP Decision Support System for Reverse Logistics Strategy Development in Online Retailing Industry. Bali: Proceedings of the 23rd ISL.

[13] Ashaf, D. H., Hidayat, W. S., \& Ahmadi. (2019). Decision Support System Determines The Purchase of House Right Using Analithical Hierarchy Process (AHP) and BORDA Methods. Surabaya: International Journal of ASRO, Vol.10 No.1. ISSN: 2722-5763.

[14] Aminudin, N., Huda, M., Ihwani, S. S., Noor, S. S., Basiron, B., Jasmi, K. A., et al. (2018). The Family Hope Program Using AHP Method. Malaysia: International Journal of Engineering \& Technology, Vol.7 No.2.

[15] Hummel JM, Rossum W van, Verkerke GJ,Rakhorst G, "The Effects of Team Expert Choice on Group Decision-Making in Coolaborative New Product Development", Journal of Multi-Criteria Decision Analysis, 9(1-3):pp 90-98, 2000.

[16] Saaty, L.Thomas, "Better World Through Better Decision Making", Proceedings of the International Symposium on the Analytic Hierarchy Process 2013. 